\title{
EFFECTS OF STAGE DROUGHT AND RE-WATERING ON PHOTOSYNTHESIS, ROOT SHOOT RATIO AND WATER USE EFFICIENCY OF SUMMER MAIZE (Zea mays L.)
}

\author{
LI, Y. B. ${ }^{1}-$ WANG, X. ${ }^{1 *}-$ ZHU, Y. N. ${ }^{1}-$ LI, D. X. ${ }^{1}-$ GAO, Y. ${ }^{2}$ \\ ${ }^{1}$ College of Water Conservancy, North China University of Water Resources and Electric \\ Power, Zhengzhou, China \\ ${ }^{2}$ Farmland irrigation research institute, Chinese Academy of Agricultural Sciences, Xinxiang, \\ China \\ "Corresponding author \\ e-mail:201510107063@stu.ncwu.edu.cn
}

(Received $9^{\text {th }}$ May 2020; accepted $29^{\text {th }} \mathrm{Jul} 2020$ )

\begin{abstract}
Field experiments were carried out to evaluate the effect of levels water stress and re-watering the growth characteristics and water use efficiency of summer maize (Zea mays L.) at different growth stages. The experiment included 3 water stress treatments at jointing-tasseling and flowering-filling stages, full water supply was set as a reference. The photosynthesis, dry matter accumulation, yield and water use efficiency were compared and analyzed under different drought and re-watering conditions. Results showed that the inhibition of photosynthesis not only occurred under of water stress, but also existed after re-watering. The degree of inhibition was related to both the degree of water stress and the growing stage. Meanwhile the degree of water stress and the growing stage were closely related to the stomatal restriction inhibiting the photosynthesis. The effects of moisture variation on dry matter distribution between root and cap were distinctive at different growing stages. The yield of maize did not significantly differ between the Treatment1, Treatment 4 and control treatments, while the water utilization efficiency of Treatment 1 and Treatment 4 was higher that of the control check. Therefore, reasonable water stress not only ensures yield, saves irrigation water, but also effectively improve water use efficiency.
\end{abstract}

Keywords: drought stress, rewater, biomass measurement, physiological measurement, water consumption

\section{Introduction}

Henan province is the greatest agricultural province and the main grain-producing region of China. Affected by the climate of the Huang-Huai-Hai river basin, the region has complex hydrometeorological conditions and frequent drought disasters. Water deficit has become a bottleneck restricting the sustainable development of agriculture (Zhang et al., 2008, 2013) and affecting agricultural production and economic development seriously (Wang et al., 2014). Water deficit is one of the main factors affecting crop growth and yield (Kulkarni and Phalke, 2009; Nielsen et al., 2009; Peng et al., 2014). The effect of water on crop and the response of crop to water are very complex, there have been published research results about it at home and abroad. Studies on the effects of drought on summer maize have been a subject of scientific interest in recent years. Wu et al. (2015) revealed that effects of drought stress at different growth stages on the growth and yield of maize in Northwest Shandong through field experiments under rain-proof shed. Ji et al. (2012) concluded that the yield variation of maize in Northeast China was closely related to the growth stage of drought by field pond planting test. Guan et al. (2012) studied the effects of early flowering on growth, physiological characteristics and yield of potted maize and compensated growth of plants after re-watering. However, 
the most of experiments were conducted under short-term drought stress at different growth stages, and there were regional differences, while the effects of short-term drought and long-term drought stress were significantly different. Barrel planting simulation experiments on maize response to persistent drought at different growth stages and even the whole growth period is still rare. Photosynthetic characteristics, root canopy and yield of maize are most directly related to drought, which a large number of studies have revealed the relationship between stomatal conductance, net photosynthetic rate and chlorophyll fluorescence of maize leaves and drought severity and growth period (Yao et al., 2012; Yu et al., 2015; Cai et al., 2017). Mangani et al. (2018) reported that drought decreased stomatal closure and photosynthesis. Other studies showed that drought significantly affected the root-shoot ratio of maize and was related to water stress, there were differences between root and shoot compensation effect in different growth period after re-watering (Li et al., 2016; Meng et al., 2016). Mi et al. (2017) through field experiments concluded that the degree of drought could quantitatively express the soil drought condition and there was a quantitative relationship between drought degree and maize yield reduction. Some studies have revealed the response of plant growth to drought and effect on yield (Kato et al., 2008; Daryanto et al., 2016, 2017; Wang et al., 2017). In addition, some studies have analyzed the growth and development, physiological processes and molecular genetic characteristics of maize in response to drought and used them to explain the effect of drought on yield (Deng et al., 2009; Zheng et al., 2010; Qi et al., 2010; Xu et al., 2017; Meng et al., 2018).

Maize is one of the most important crops in China and summer maize is a major food crop in North Plain China. As the main autumn grain, summer maize often suffered from drought during its growing period, which seriously affected the growth and final yield of crops and caused great agricultural economic losses. It is very important to study the effects of different degrees of drought after re-watering on maize growth and yield at different stages, and to determine the boundary thresholds of water demand time and quantity for drought recovery. It is the basic work of optimizing irrigation system and efficient utilization of water resources. Although there is a lot of research on maize under drought conditions, there is still no systematic and in-depth experimental study on the effects of re-watering on physiological characteristics and yield of maize after drought. Therefore, summer maize which the main economic crops in Huang-Huai-Hai Plain was taken as the research object, studied the effects of water deficit and re-watering at different growth stages on the growth and physiological characteristics of summer maize and analyzed the mechanism of photosynthetic characteristics, root cap and yield responses to drought of summer maize, which provided a certain technical basis for optimizing irrigation schedule and forecasting the influence of drought stress on the development trend of maize.

\section{Materials and methods}

\section{Experimental design}

The experiment was carried out in the barrel planting experimental area under the rainproof shed at Comprehensive Experimental Base of CHINESE ACADEMY OF AGRICULTURAL SCIENCES $\left(35^{\circ} 18^{\prime} \mathrm{N}, 113^{\circ} 54^{\prime} \mathrm{E}\right.$, Height $\left.81 \mathrm{~m}\right)$ from June to October, 2017. The average temperature of the area is $14{ }^{\circ} \mathrm{C}$, the frostless period is $210 \mathrm{~d}$, the sunshine time is $2399 \mathrm{~h}$ and the precipitation is $580 \mathrm{~mm}$. The summer maize variety was Denghai 605 which was suitable for farming in Henan province, with good adaptability, 
good stable yield and high yield. They were sown on June 10, 2017, with two plants per barrel at three-leaf period. Water treatment at different growth stages is shown in Table 1. The water stress was set at four levels, such as full water supply, slight water stress, moderate water stress, severe water stress at jointing-tasseling stage and flowering-filling stage. The soil water content was controlled at 70\%-80\%, 60\%-70\%, 50\%-60\% and 40\%-50\% of field moisture capacity, respectively, expressed by CK, L, M and S. The experiment consisted of 7 treatments and each treatment was repeated 3 times. Soil moisture was controlled by daily weighing, and the daily amount of irrigation was the difference between the barrel weight of the adjacent two days, which is calculated in $60 \mathrm{~cm}$ deep soil layer and was measured accurately by measuring cylinder. The soil moisture content in the planned moisture layer $(0-60 \mathrm{~cm})$ was determined by drying method every 5 days, so that the irrigation could reach the upper limit of water control. The diameter and height of the test barrel were $40 \mathrm{~cm}$ and $60 \mathrm{~cm}$, respectively. The compound fertilizer was applied at $10 \mathrm{~g}$ per barrel $(2: 1$ ratio of $\mathrm{N}: \mathrm{P})$, and the soil bulk density of each barrel was controlled at $1.36 \mathrm{~g} / \mathrm{cm}$. All P and $\mathrm{K}$ fertilizers applied to summer maize were basal application.

Table 1. Barrel planting test treatment

\begin{tabular}{c|c|c|c|c}
\hline Water treatment & Seedling stage & $\begin{array}{c}\text { Jointing-tasseling } \\
\text { stage }\end{array}$ & $\begin{array}{c}\text { Flowering-filling } \\
\text { stage }\end{array}$ & Milking stage \\
\hline $\mathrm{CK}$ & $\mathrm{CK}$ & $\mathrm{CK}$ & $\mathrm{CK}$ & $\mathrm{CK}$ \\
$\mathrm{T} 1$ & $\mathrm{CK}$ & $\mathrm{L}$ & $\mathrm{CK}$ & $\mathrm{CK}$ \\
$\mathrm{T} 2$ & $\mathrm{CK}$ & $\mathrm{M}$ & $\mathrm{CK}$ & $\mathrm{CK}$ \\
$\mathrm{T} 3$ & $\mathrm{CK}$ & $\mathrm{S}$ & $\mathrm{CK}$ & $\mathrm{CK}$ \\
$\mathrm{T} 4$ & $\mathrm{CK}$ & $\mathrm{CK}$ & $\mathrm{L}$ & $\mathrm{CK}$ \\
$\mathrm{T} 5$ & $\mathrm{CK}$ & $\mathrm{CK}$ & $\mathrm{M}$ & $\mathrm{CK}$ \\
$\mathrm{T} 6$ & $\mathrm{CK}$ & $\mathrm{CK}$ & $\mathrm{S}$ & $\mathrm{CK}$ \\
\hline
\end{tabular}

\section{Observation items}

\section{Determination of soil moisture content}

The irrigation amount was measured and recorded every day, then calculated soil moisture by the weighting method. The soil moisture content in the planned moisture layer $(0-60 \mathrm{~cm})$ was measured by drying method every 5 days after the begin of drought treatment, and taken soil sample every $20 \mathrm{~cm}$ to determine the irrigation amount. The formula was as follows:

$$
W=\gamma H A\left(W_{s}-W_{o}\right)
$$

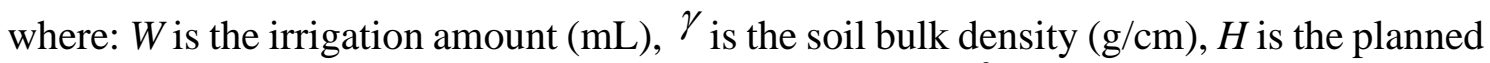
moisture layer $(\mathrm{cm}), A$ is the surface area of the barrel $\left(\mathrm{cm}^{2}\right), W_{s}(\%)$ is the upper limit of design irrigation and $W_{0}(\%)$ is the measured soil moisture content before irrigation.

\section{Leaf photosynthesis parameters}

Leaf photosynthetic rate $\mathrm{P}_{\mathrm{n}}$ was measured by LI-6000 portable photosynthetic apparatus (LI-COR, USA) from 9:00 to 11:00, and stomatal conductance $\mathrm{G}_{\mathrm{s}}$ was 
measured by AP4 plant porometer at jointing-tasseling stage and flowering-filling stage, respectively, weather is sunny and calm. The concentration of $\mathrm{CO}_{2}$ was set at $400 \mu \mathrm{mol} / \mathrm{mol}$, the flow rate was set at $500 \mu \mathrm{mol} /\left(\mathrm{m}^{2} \cdot \mathrm{s}^{2}\right)$, and the light intensity was set at $1000 \mathrm{mmol} /\left(\mathrm{m}^{2} \cdot \mathrm{s}^{2}\right)$ which was provided by the LED of the system-self. The third leaf from the top of maize was selected at jointing stage, which grew in the same direction, and the leaf position was consistent and fully expanded. Then three ear-leaves with uniform growth and light direction were selected at tasseling-filling stage. The photosynthetic rate was measured on the 0,1 and 10 days after re-watering, and repeated three times for each treatment.

\section{Root acquisition}

During the milk stage of maize, firstly, the above-ground plants were cut off, second, the soil column that contain the root system was removed from the barrel to put into the prepared nylon net bag and soaked in the pool until the soil column becomes loose, then washed clean and dried finally. The dry weight of the root, canopy, ear, stem and leaf of the maize per plant were measured respectively and repeated three times for each treatment.

\section{Biomass measurement}

During the milk stage of maize, the above-ground biomass was classified according to the stem, leaf and ear organs. Then the samples were packed in a constant temperature drying oven and heated. The temperature of deactivation of enzymes in $100^{\circ} \mathrm{C}-105^{\circ} \mathrm{C}$ for 0.5 hours, and then maintained at $70-80^{\circ} \mathrm{C}$. After a week (The quality of the plant was constant), the dry matter of maize was weighed according to stem, leaf and ear.

\section{Yield}

After harvested artificially, threshed and dried, then grain number per spike and 100 -grain weight were measured.

\section{Water consumption}

The water consumption of maize was calculated by water balance method. The maize experiment was conducted in barrel planting under rain-proof shed, so the rainfall, surface runoff and groundwater recharge could be neglected. Therefore, the formula of water consumption can be simplified to:

$$
E T=\Delta W+I
$$

where: $E T$ is water consumption $(\mathrm{mm}), \Delta W$ is $0 \sim 60 \mathrm{~cm}$ soil water storage change, $I$ is irrigation amount (mm).

WUE is defined as:

$$
W U E=\frac{Y}{E T}
$$

where: WUE is water use efficiency $\left(\mathrm{g} / \mathrm{m}^{2} \cdot \mathrm{mm}\right), Y$ is yield $(\mathrm{g})$. 


\section{Statistical analysis}

Microsoft Excel and DPS 12.01 software were used for statistical analysis, and the least significant difference (LSD) method was used for the significance test with $\mathrm{P}<0.05$ level and analysis of variance (ANOVA).

\section{Result analysis}

\section{The effect of re-watering on stomatal conductance and net photosynthetic rate of maize at different growth stages after water stress}

Fig. 1 and Fig. 2 showed the change of stomatal conductance and net photosynthetic rate of maize under different water stress and re-watering later at two different growth stages. The stomatal conductance and net photosynthetic rate of maize leaves showed a gradual decline trend with the intensification of water stress. The more serious the water stress, the more obvious the decrease of stomatal conductance and net photosynthetic rate. Compared with CK, the stomatal conductance of T1 to T3 decreased by $26.6 \%, 40.1 \%$ and $64.8 \%$, and the net photosynthetic rate decreased by $13.7 \%, 25.8 \%, 34.3 \%$, the stomatal conductance of T4 to T6 decreased by $23.5 \%, 60.7 \%$ and $75.5 \%$, and the net photosynthetic rate decreased by $4.1 \%, 17.4 \%$ and $62.4 \%$ respectively, the stomatal conductance and net photosynthetic rate with T1 to T6 showed significant difference with CK. After 1 day of re-watering the stomatal conductance and net photosynthetic rate of maize leaves were restored, but there were still significant differences between $\mathrm{T} 1$ to $\mathrm{T} 6$ from CK. Because the compensation effect usually needed a period of adjustment. After 10 days of re-watering, the stomatal conductance and net photosynthetic rate of maize began to recover significantly after different water stress treatments. There was no significant difference between $\mathrm{T} 1, \mathrm{~T} 2$ and $\mathrm{T} 3$ in stomatal conductance and net photosynthetic rate, but there was still significant difference with $\mathrm{CK}$. The stomatal conductance and net photosynthetic rate of T4 began to recover greatly, there was no significant difference with $\mathrm{CK}$. But the stomatal conductance and net photosynthetic rate recovery of maize with T5 and T6 were limited, and there was a significant difference with CK. The stomatal conductance and net photosynthetic rate of maize at flowering-filling stage were significantly lower than jointing-tasseling stage after re-watering for 10 days under the same water stress treatments. Results indicated that the inhibition of photosynthesis not only occurred in the control process of water stress, but was still inhibited to some extent after re-watering, and the degree of inhibition was related to the degree of stress and growth stage.
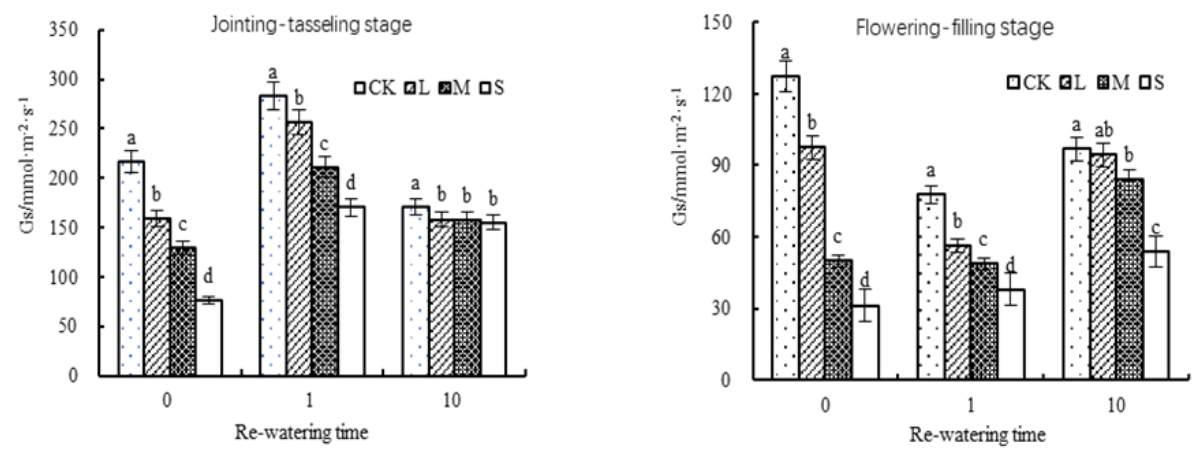

Figure 1. Effects of re-watering on stomatal conductance of maize under water stress at different growth stages 

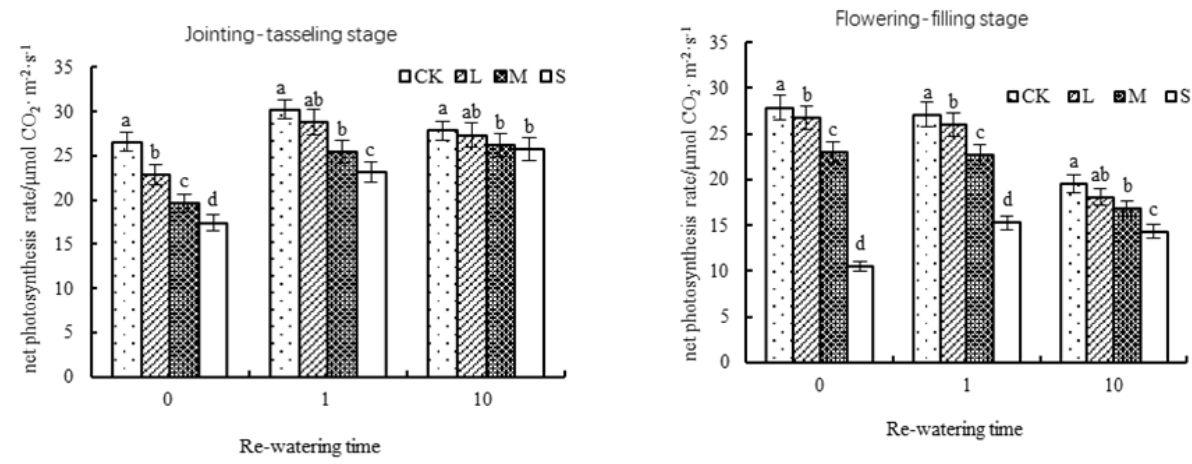

Figure 2. Effects of re-watering on net photosynthetic rate of maize under water stress at different growth stage

\section{The effect of re-watering on dry matter distribution, root shoot ratio and yield of maize at different growth stages after water stress}

The changed of dry matter distribution, root-shoot ratio and yield of maize under different water stress conditions were listed in Table 2. There was significant difference between the root dry weight and the crown dry weight per plant in T2, T3, T5 and T6 with CK, T1 and T4 was no significant difference, which indicated that water stress can inhibit the root and crown growth of maize. With the intensive of water stress, $\mathrm{CK}>\mathrm{T} 1>\mathrm{T} 2>\mathrm{T} 3, \mathrm{CK}>\mathrm{T} 4>\mathrm{T} 5>\mathrm{T} 6$, the root and the crown dry weight per plant of maize showed a decreasing trend. Water stress inhibited the growth and development of maize canopy and root system, the dry weight of canopy and root system were lower than CK in all treatments. However, the root-shoot ratio of T6>T5>T4>CK, T3>T2>T1>CK was found by compared the root-shoot ratio of each treatment. Results indicated that water stress inhibited the growth and development of root system more severe than the canopy, and $\mathrm{T} 6>\mathrm{T} 3, \mathrm{~T} 5>\mathrm{T} 2, \mathrm{~T} 4>\mathrm{T} 1$ showed the root-crown ratio of maize from flowering to filling stage was higher than that from jointing stage to heading stage under the same water stress. It showed that dry weight of stem and leaf per plant of maize was T6>T5>T4>CK, T3>T2>T1>CK in the Table 2, with the aggravation of water stress, dry weight of stem and leaf per plant increased gradually, the dry weight of per ear was $\mathrm{CK}>\mathrm{T} 1>\mathrm{T} 2>\mathrm{T} 3, \mathrm{CK}>\mathrm{T} 4>\mathrm{T} 5>\mathrm{T} 6$, the dry weight per ear showed a decreasing trend with the aggravation of water stress. Results indicated that with the intensification of water stress, the dry matter accumulation of each organs of maize under different water stress showed the same trend. The proportion of dry matter accumulation of stem and leaf per plant increased gradually, and the proportion of dry matter accumulation of spike per plant decreased gradually. Compared the grain number per ear and yield per plant, it showed that $\mathrm{CK}>\mathrm{T} 1>\mathrm{T} 2>\mathrm{T} 3, \mathrm{CK}>\mathrm{T} 4>\mathrm{T} 5>\mathrm{T} 6$, water stress from jointing stage to tasseling stage and flowering stage to filling stage can reduce the grain number per ear and yield per plant. They were negatively correlated, that was, the greater the degree of stress the grain number per ear and yield per plant of maize were smaller, meanwhile, $\mathrm{T} 1>\mathrm{T} 4, \mathrm{~T} 2>\mathrm{T} 5, \mathrm{~T} 3>\mathrm{T} 6$, under the same water stress the grain number per ear and yield per plant from jointing stage to tasseling stage was higher than flowering stage to filling stage. Compared the 100-grain weight of maize, T6>T5>T4>CK, T3>T2>T1>CK, water stress from jointing to tasseling stage and flowering to filling stage will increase the 100 -grain weight of maize, moreover 100-grain weight is positively related to the degree 
of water stress, that was, the greater the degree of stress the greater the 100-grain weight of maize.

Table 2. Dry matter, root shoot ratio and yield of maize at different growth stages under water stress and re-watering conditions

\begin{tabular}{|c|c|c|c|c|}
\hline $\begin{array}{c}\text { Water } \\
\text { treatment }\end{array}$ & $\begin{array}{l}\text { Dry weight of root } \\
\text { per plant } \\
\text { (g) }\end{array}$ & $\begin{array}{c}\text { Dry weight of Stem and } \\
\text { leaf per plant } \\
\text { (g) }\end{array}$ & $\begin{array}{l}\text { Dry weight of shoot } \\
\text { per plant } \\
\text { (g) }\end{array}$ & Root-shoot ratio \\
\hline CK & $6.35^{\mathrm{a}}$ & $54.95^{\mathrm{b}}$ & $182^{\mathrm{a}}$ & $0.034^{\mathrm{b}}$ \\
\hline $\mathrm{T} 1$ & $6.05^{\mathrm{a}}$ & $81.72^{\mathrm{a}}$ & $167.61^{\mathrm{a}}$ & $0.036^{\mathrm{b}}$ \\
\hline $\mathrm{T} 2$ & $5.64^{\mathrm{b}}$ & $83.46^{\mathrm{a}}$ & $127.67^{\mathrm{b}}$ & $0.044^{\mathrm{a}}$ \\
\hline $\mathrm{T} 3$ & $5.46^{\mathrm{c}}$ & $85.79^{a}$ & $119.14^{\mathrm{b}}$ & $0.046^{\mathrm{a}}$ \\
\hline $\mathrm{T} 4$ & $5.86^{\mathrm{a}}$ & $83.23^{\mathrm{a}}$ & $158.07^{\mathrm{a}}$ & $0.037^{\mathrm{b}}$ \\
\hline $\mathrm{T} 5$ & $5.24^{\mathrm{c}}$ & $84.44^{\mathrm{a}}$ & $117.78^{\mathrm{b}}$ & $0.045^{\mathrm{a}}$ \\
\hline T6 & $4.71^{\mathrm{d}}$ & $91.16^{\mathrm{a}}$ & $93.97^{\mathrm{c}}$ & $0.05^{\mathrm{a}}$ \\
\hline $\begin{array}{c}\text { Water } \\
\text { treatment }\end{array}$ & \begin{tabular}{|c|}
$\begin{array}{c}\text { Dry weight of spike } \\
\text { per plant } \\
\text { (g) }\end{array}$ \\
\end{tabular} & Grain number per spike & $\begin{array}{c}\text { Hundred-grain } \\
\text { weight } \\
\text { (g) }\end{array}$ & $\begin{array}{l}\text { Yield per plant } \\
\text { (g) }\end{array}$ \\
\hline CK & $127.05^{\mathrm{a}}$ & $364^{\mathrm{a}}$ & $28^{\mathrm{c}}$ & $57.95^{\mathrm{a}}$ \\
\hline $\mathrm{T} 1$ & $85.89^{a}$ & $165^{\mathrm{b}}$ & $35.93^{\mathrm{bc}}$ & $56.02^{\mathrm{a}}$ \\
\hline $\mathrm{T} 2$ & $44.21^{\mathrm{b}}$ & $109^{\mathrm{bc}}$ & $40.76^{\mathrm{b}}$ & $43.33^{\mathrm{b}}$ \\
\hline $\mathrm{T} 3$ & $33.35^{\mathrm{b}}$ & $96^{c}$ & $43.52^{\mathrm{b}}$ & $37.42^{\mathrm{b}}$ \\
\hline $\mathrm{T} 4$ & $74.84^{\mathrm{a}}$ & $147^{\mathrm{b}}$ & $33.8^{\mathrm{bc}}$ & $54.18^{\mathrm{a}}$ \\
\hline T5 & $33.34^{\mathrm{b}}$ & $99^{c}$ & $42.28^{b c}$ & $38.77^{\mathrm{b}}$ \\
\hline T6 & $2.81^{\mathrm{c}}$ & $14^{\mathrm{d}}$ & $48.88^{\mathrm{a}}$ & $2.07^{\mathrm{c}}$ \\
\hline
\end{tabular}

Note: same letter in each column indicates no significant difference at 0.05 level, while difference letters mean significant difference at 0.05 level $(p<0.05)$

\section{The effect of water stress on yield and water use efficiency of maize at different growth stages}

The changed of maize yield and water use efficiency (WUE) under water stress at different growth stages were listed in Table 3. It showed that the water consumption and yield under T1 and T4 were lower than CK, but the WUE of T1 was the best, T4 was also higher than CK, which indicated that the suitable water (slight water stress) conditions were beneficial to the growth and development of summer maize and the distribution of dry matter in various organs. The water consumption of $\mathrm{T} 1<\mathrm{T} 4, \mathrm{~T} 2<\mathrm{T} 5, \mathrm{~T} 3<\mathrm{T} 6$, under same water stress the water consumption of maize at jointing-tasseling stage were lower than that at flowering-filling stage, but from the point of yield and WUE, T1>T4, T2>T5, T3>T6 which showed from analysis Table 3, the yield and WUE at jointing-tasseling stage were higher than that at flowering-filling stage. Results indicated that water condition was crucial of maize which can significantly reduce the yield and WUE at flowering-filling stage. The same as at jointing-tasseling stage water stress can also significantly reduce the yield, but the effect on WUE was not significant.

Therefore, when the WUE reached the maximum value, the yield did not reach the optimal value, it showed that the single-sided pursuit of the best maize yield, the WUE could not get the best, which will inevitably lead to waste of water resources. 
Table 3. Yield and WUE of maize at different growth stages under water stress

\begin{tabular}{c|c|c|c}
\hline Water treatment & $\begin{array}{c}\text { Yield } \\
(\mathbf{g} / \mathbf{b b l})\end{array}$ & $\begin{array}{c}\text { Water consumption } \\
(\mathbf{m m})\end{array}$ & $\begin{array}{c}\text { WUE } \\
\left(\mathbf{g} / \mathbf{m}^{\mathbf{2}} \cdot \mathbf{m m}\right)\end{array}$ \\
\hline CK & $115.89^{\mathrm{a}}$ & 297.33 & $1.38^{\mathrm{b}}$ \\
T1 & $112.04^{\mathrm{a}}$ & 263.79 & $1.50^{\mathrm{a}}$ \\
T2 & $86.67^{\mathrm{b}}$ & 252.47 & $1.21^{\mathrm{b}}$ \\
T3 & $74.84^{\mathrm{c}}$ & 247.70 & $1.07^{\mathrm{c}}$ \\
T4 & $108.35^{\mathrm{a}}$ & 270.56 & $1.42^{\mathrm{b}}$ \\
T5 & $77.54^{\mathrm{c}}$ & 258.49 & $1.06^{\mathrm{c}}$ \\
T6 & $4.14^{\mathrm{d}}$ & 251.95 & $0.06^{\mathrm{d}}$ \\
\hline
\end{tabular}

Note: same letter in each column indicates no significant difference at 0.05 level, while difference letters mean significant difference at 0.05 level $(\mathrm{p}<0.05)$

\section{Discussion}

Under water stress, the photosynthetic ability of maize was inhibited, and the degree of inhibition increased with the aggravation of water stress. The compensation effect of maize after re-watering had an adjustment period. After 10 days, the differences in net photosynthetic rate and stomatal conductance between $\mathrm{T} 1$ to $\mathrm{T} 5$ and $\mathrm{CK}$ were significantly reduced, it may be that stomata were main factors affected photosynthetic characteristics under mild water stress, the stomatal resistance of leaves decreased and the limitation of $\mathrm{CO}_{2}$ absorption was weakened for the stomatal, so photosynthesis of maize could recover quickly after re-watering (Yao et al., 2012). The main reasons for the significant difference of net photosynthetic rate and stomatal conductance between T6 and CK were the changes of hormone level, which metabolic disorders that destroy the structure and function of chloroplasts and cause permanent damage to mesophyll cells in leaves under severe water stress (Liu et al., 2012; Pan et al., 2015). The chlorophyll content decreased due to damage of leaf cell, therefore photosynthesis was inhibited even though stomatal resistance decreased after re-watering. The inhibitory action of water stress on Photosynthesis of maize was not only in the process of water stress but also in re-watering. The degree of inhibition varies with the degree of water stress and the growth stage of maize, and the degree of water stress and growth stage are closely related to the stomatal restriction inhibits photosynthesis of maize. Photosynthesis of maize was sensitive to water stress during flowering-filling stage. After 10 days of re-watering, the stomatal conductance and the net photosynthetic rate of T6 were significantly decreased by $44.5 \%$ and $26.7 \%$ compared with CK, respectively.

The results showed that water stress could significantly inhibit the root and crown growth of maize, and the treatment of moderate and severe water stress was significantly different from CK. The accumulation of dry matter in the stem and leaf organs of maize was significantly inhibited by water stress in the jointing - tasseling stage, mainly because the jointing-tasseling stage was the key period of maize vegetative growth (Xing et al., 2010), during this time, water stress affected the growth cell division of maize, resulting in short stalks and leaves. Water stress at flowering-filling stage had a great influence on yield, because it at flowering-filling stage seriously affected the differentiation of ear, reduced the activity of filament and pollen, and decreased the success rate of fertilization, thus leading to the reduction of seed number (Tian et al., 2013). Water stress increased the hundred-grain weight of maize which was similar to the result of the study that 
drought on the dry matter distribution of foxtail millet by Zhang et al. (2016). Water stress could reduce the proportion of ears distribution and increase the proportion of stems and leaves distribution, which was contrary to the results of spring wheat by Chen et al. (2017). Water stress inhibited the growth of maize root and crown, and the heavier the stress the larger the root-shoot ratio. From the perspective of different growth stages, water stress can increase the root-shoot ratio of maize, but water changed in different stages have different effected on the distribution ratio of dry matter between roots and crowns. The effected of water stress on increasing the root-shoot ratio during floweringfilling stage was higher than jointing-tasseling stage. In addition, the change of root-shoot ratio was consistent regardless of the degree of water stress.

The amount of irrigation water significantly affected the WUE of summer maize. After water stress and rewater with $\mathrm{T} 1$ and $\mathrm{T} 4$, the yield of summer maize per barrel was no different from CK but the WUE was higher than CK, increased by $8.7 \%$ and $2.8 \%$ respectively. Some compensation effects also appeared after re-watering with other water stress treatments but results were not obvious, both yield and WUE per barrel were lower than CK. Therefore, during the whole growth and development stage of summer maize, reasonable water stress should be carried out according to the water requirement characteristics of each growth period and the compensation law of re-watering after water stress, which not only gives full play to the compensation effect, but also guarantees the yield and reaches the goal of improving water use efficiency.

\section{Conclusion}

(1) The re-watering test after water stress indicated that the photosynthesis was inhibited not only during the control process of water stress, but also after re-watering. The degree of inhibition varies with the degree of water stress and the growth stage of maize, then the degree of water stress and growth stage were closely related to stomatal restriction inhibits photosynthesis. The stomatal conductance and net photosynthetic rate of re-watering of maize under severe water stress at flowering-filling stage were more difficult to recover than those at jointing-tasseling stage.

(2) In terms of different growth stages, water stress can increase the root-shoot ratio of maize, but the water change in different stages had different effect on the distribution ratio of dry matter between roots and crowns. The effect of water stress on root-shoot ratio was more obvious in the flowering-filling stage.

(3) The yield and WUE of maize decreased with the increase of water stress at jointing-tasseling stage and flowering-filling stage. The yield of maize under slight water stress showed no significant difference from CK and the WUE was higher than CK, the WUE of maize under $\mathrm{T} 1$ and $\mathrm{T} 4$ was improved by $8.7 \%$ and $2.8 \%$ compared with $\mathrm{CK}$, respectively. Therefore, reasonable water stress (slight water stress) during jointing-tasseling and flowering-filling stages can guarantee yield, saves irrigation water and effectively improves WUE. The slight drought stress at jointing-tasseling stage and re-watering was the best.

(4) The experiment studied the relationship between water and yield, but it did not reveal the specific quantitative relationship of the influence of water deficit on yield loss at each growth stage of maize, and the specific quantitative relationship between yield reduction rate and water consumption should be further studied through repeated tests. Although some experimental results of summer maize drought re-watering were obtained 
by means of barrel cultivation, in the next, further verification and research should be carried out in combination with field experiment.

Acknowledgements. We are grateful to the research grants from the National Natural Science Foundation of China (51779093) and Supported by Program for Innovative Research Team (in science and Technology) in University of Henan Province (17IRTSTHN026), Supported by Innovation fund for doctoral students of North China University of Water Resources and Electric Power.

\section{REFERENCES}

[1] Cai, F., Mi, N., Ji, R. P., Ming, H. Q., Xie, Y. B., Yu, W. Y., Zhang, Y. S., Gao, L. L. (2017): Effects of continuous drought stress during key growth phases on photosynthetic characteristics of spring maize in Northeast China. - Chinese Journal of Ecology 36(6): 1578-1589.

[2] Chen, F., Wang, R. Y., Wang, H., Zhao, H., Zhang, K., Zhao, F. N. (2017): Dry Matter Accumulation and Distribution of Spring Wheat under Drought Stress. - Arid Zone Reaserch 34(6): 1418-1425.

[3] Daryanto, S., Wang, L., Jacinthe, P. (2016): Global Synthesis of Drought Effects on Maize and Wheat Production. - PloS one, doi.org/10.1371/journal.pone.0156362.

[4] Daryanto, S., Wang, L., Jacinthe, P. (2017): Global synthesis of drought effects on cereal, legume, tuber and root crops production: A review. - Agricultural Water Management 179: 18-33.

[5] Deng, X. F., Fu, F. L., Ni, N., Li, W. C. (2009): Differential Gene Expression in Response to Drought Stress in Maize Seedling. - Agricultural Sciences in China 8(7): 767-776.

[6] Guan, Y. X., Dai, J. Y., Xu, S. C. (2012): Effects of Soil Drought During Flowering and Re-watering on Plant Compensative Growth and Yield of Maize. - Acta Agronomica Sinica 6: 102-107.

[7] Ji, R. P., Che, Y. S., Zhu, Y. N., Liang, T., Feng, Y., Yu, W. Y., Zhang, Y. S. (2012): Impacts of drought stress on the growth and development and grain yield of spring maize in Northeast China. - Chinese Journal of Applied Ecology 23(11): 3021-3026.

[8] Kato, Y., Hirotsu, S., Nemoto, K., Yamagishi, J. (2008): Identification of QTLs controlling rice drought tolerance at seedling stage in hydroponic culture. - Euphytica 160(3): 423430.

[9] Kulkarni, M., Phalke, S. (2009): Evaluating variability of root size system and its constitutive traits in hot pepper (Capsicum annum L.) under water stress. - Scientia Horticulturae 120(2): 159-166.

[10] Li, M. D., Zhang, H. P. (2016): Effects of Water Stress and Re-watering on the Dry Matter Accumulation, Root Shoot Ratio and Yield of Pea. - Journal of Desert Research 36(4): 1034-1040.

[11] Li, M., Chu, R. H., Yu, Q., Towfiqul Islam, A. R. Md., Chou, S. R., Shen, S. H. (2017): Evaluating Structural, Chlorophyll-Based and Photochemical Indices to Detect Summer Maize Responses to Continuous Water Stress. - Water 10(4): 500.

[12] Liu, L. P., Ouyang, Z., Wu, L. F., Li, F. D., Liu, P. F. (2012): Effects of phased drought and re-watering on the photosynthetic characteristics and gain yield of winter wheat. Chinese Journal of Ecology 31(11): 2797-2803.

[13] Mangani, R., Tesfamariam, E., Bellocchi, G., Hassen, A. (2018): Growth, development, leaf gaseous exchange, and grain yield response of maize cultivars to drought and flooding stress. - Sustainability 10(10): 3492.

[14] Meng, Z. J., Duan, A. W., Wang, X. S., Gao, Y., Shen, J. J. (2016): Effect of Regulated Deficit Irrigation on Growth Relation of Root and Shoot in Cotton. - Transactions of the Chinese Society for Agricultural Machinery 47(4): 99-104. 
[15] Mi, N., Cai, F., Zhang, Y. S., Ji, R. P., Yu, W. Y., Zhang, S. J., Fang, Y. (2017): Effects of continuous drought during different growth stages on maize and it quantitative relationship with yield loss. - Chinese Journal of Applied Ecology 28(5): 1563-1570.

[16] Nielsen, D. C., Vigil, M. F., Benjamin, J. G. (2009): The variable response of dryland corn yield to soil water content at planting. - Agricultural Water Management 96(2): 330-336.

[17] Pan, Z. Y., Zhao, Y. H., Chen, J., Pan, Z. T., Tang, G., Peng, Z. H. (2015): Effect of Drought Stress in Different Growth Stages on Maize Kernel Yield and Ear characteristics. - Journal of Mountain Agricultural Biology 3: 86-88.

[18] Peng, Y. L., Zhao, X. Q., Ren, J. W., Li, J. Y. (2014): Genotypic differences in response of physiological characteristics and grain yield of maize inbred lines to drought stress at flowering stage. - Agricultural Research in Arid Areas 32(3): 9-14.

[19] Qi, W., Zhang, J. W., Wang, K. J., Liu, P., Dong, S. T. (2010): Effects of drought stress on the grain yield and root physiological traits of maize varieties with different drought tolerance. - Chinese Journal of Applied Ecology 21(1): 48-52.

[20] Seregin, I. V., Kozhevnikova, A. D. (2004): Strontium Transport, Distribution, and Toxic Effects on Maize Seedling Growth. - Russian Journal of Plant Physiology 51(2): 215-221.

[21] Tian, L., Xie, X. J., Bao, Y. X., Hu, J. C., Yu, L., Wang, J. X. (2013): Effects of Moisture Stress on Photosynthetic Characteristics of Summer Maize Leaf during Growth Stages. Chinese Journal of Agrometeorology 34(06): 655-660.

[22] Wang, G. Q., Wang, Y., Zhang, M. (2014): Runoff Variations and Its Responses to Precipitation Changes in Huang-Huai-Hai River Basin. - Yellow River 1: 52-54.

[23] Wang, F., Li, P., Xiong, Y., Chen, J. Z., Lin, L. R. (2017): Effects of Different Drought Degrees on Summer Maize Growth and Yield. - Water Saving Irrigation 2: 1-4, 8.

[24] Wu, Z. X., Wang, Y. J., Li, M. H., Xue, X. P. (2015): The Effect of Drought Stress on the Development and Yield of Summer Maize in Northwest Shandong Province. - Journal of Shandong Agricultural University (Natura Science Edition) 6: 817-821.

[25] Xing, Y. Y., Zhang, F. C., Wang, X. K. (2010): Effects of water deficit irrigation and nitrogen nutrition on maize growth at different growth stages. - Agricultural Research in the Arid Areas 6: 1-6.

[26] Xu, T. J., Lv, T. F., Zhao, J. L., Wang, R. H. (2017): Response of Maize Varieties with Different Genotypes to Drought Stress at Three Critical Stages and Drought-resistant Identification. - Journal of Agriculture 7(12): 12-17.

[27] Yao, C. X., Zhang, S. Q., Yan, X. J. (2012): Effects of drought and re-watering on photosynthetic characteristics of maize leaf. - Research of Soil and Water Conservation 19(3): 278-283.

[28] Yu, W. Y., Ji, R. P., Feng, R., Zhao, X. L., Zhang, Y. S. (2015): Response of water stress on photosynthetic characteristics and water use efficiency of maize leaves in different growth stage. - Acta Ecologica Sinica 35(9): 2902-2909.

[29] Zhang, L. P., Chen, X. F., Zhao, Z. P., Hu, Z. F. (2008): Progress in Study of Climate Change Impacts on Hydrology and Water Resources. - Progress in Geography 27(3): 6067.

[30] Zhang, S. L., Yu, P. T., Zhang, H. J., Gao, W., Wang, Y. H. (2013): Impact of climate change on the hydrological process in medium scale basin of arid areas. - Journal of Arid Land Resources and Environment 27(10): 70-74.

[31] Zhang, Y. N., Du, J. Z., Wang, Y. L. (2016): Effect of drought stress on dry matter accumulation and yield of summer millet. - Journal of Northeast Agricultural University 47(12): $15-22$.

[32] Zheng, J., Fu, J. J., Gou, M. Y., Hua, J. L., Liu, Y. J., Jian, M., Huang, Q. S., Guo, X. Y., Dong, Z. G., Wang, H. Z., Wang, G. Y. (2010): Genome-wide transcriptome analysis of two maize inbred lines under drought stress. - Plant Molecular Biology 72: 407-421. 